\title{
Context Diversity Predicts the Extent to Which the American Identity Is Implicitly Associated with Asian Americans and European Americans
}

\author{
Thierry Devos \& Melody Sadler
}

San Diego State University

This is a postprint/accepted version of the manuscript. It is now published:

Devos, T., \& Sadler, M. (2019). Context diversity predicts the extent to which the American identity is implicitly associated with Asian Americans and European Americans. Asian American Journal of Psychology, 10, 182-193. https://doi.org/10.1037/aap0000149

Please cite the published version. The version available on PsyArXiv is before journal proof. The published version might be slightly different.

\section{Author Note}

Correspondence concerning this article should be addressed to Thierry Devos, Department of Psychology, San Diego State University, 5500 Campanile Drive, San Diego, CA 92182-4611. Email: tdevos@sdsu.edu.

Study materials and the full dataset used for the present research are publicly available at https://osf.io/cpmfk/. Data files and analysis scripts necessary to reproduce the findings reported are publicly available at https://osf.io/ufxny/. We would like to thank Project Implicit for ongoing efforts to collect and make public IAT data across tasks and time.

Word count text: 8,615

Word count abstract: 249 


\begin{abstract}
Prior research documents that Asian Americans are implicitly seen as less American than European Americans (implicit American = White effect). The aim of the present research was to test whether this effect is weaker in more ethnically diverse metropolitan areas. Data from the 2010 U.S. Census were utilized to compute three indicators of context ethnic diversity: minority representation, variety, and integration. Implicit ethnic-American associations were assessed using data collected through Project Implicit. A total of 304 metropolitan areas were included in the analyses. The sample $(N=271,006)$ included $44.8 \%$ White and $31.7 \%$ Asian participants; it was composed mostly of relatively young adults $(M=26.54, S D=11.16)$ and included more women (60.9\%) than men. Respondents completed an Implicit Association Test measuring associations between the concepts "American" vs. "foreign" and two ethnic groups ("Asian American" vs. "European American”). Data were analyzed using multilevel modeling. The implicit American $=$ White effect was less pronounced in metropolitan areas characterized by higher proportions of Asian Americans (minority representation). The presence of multiple ethnic groups (variety) was associated with a weaker implicit American $=$ White effect only when minority representation was high. Greater dispersion of ethnic groups at the neighborhood level (integration) was not a source of reliable variation in implicit ethnic-American associations. These findings highlight the value of a multi-faceted perspective on context ethnic diversity. The extent to which the American identity is implicitly associated with Asian Americans and European Americans fluctuates as a function of socio-structural characteristics of local contexts.
\end{abstract}

Keywords: implicit; automatic; stereotyping; national identity; diversity; ethnicity 
Significance statement: The present research documents that the American identity is more strongly associated with Asian Americans among individuals living in U.S. metropolitan areas characterized by a larger proportion of Asian residents or a more multiethnic population. This work contributes to draw connections between beliefs about Asian American communities and characteristics of the local contexts in which individuals are immersed. 
Context Diversity Predicts the Extent to Which the American Identity Is Implicitly Associated with Asian Americans and European Americans

Despite the U.S. being considered a multiethnic society, Asian Americans are often perceived as perpetual foreigners (Lee, Wong, \& Alvarez, 2009). There is no shortage of anecdotal and scientific evidence reflecting that the American identity is not easily linked to Asian Americans (Armenta et al., 2013; Sue, Bucceri, Lin, Nadal, \& Torino, 2007). Behind inquiries about someone's origin (e.g., "where are you from?") or compliment for mastering the English language (e.g., "I am impressed with your English") may lurk the perpetual foreigner stereotype. As the U.S. population is becoming more ethnically diverse (Farrell \& Lee, 2011; Iceland, 2009; Lee \& Bean, 2010; Lee, Iceland, \& Farrell, 2014), one may wonder to what extent the propensity to view Asian Americans as perpetual foreigners varies as a function of the ethnic diversity of local contexts. Are ethnically diverse contexts characterized by a more inclusive definition of what it means to be American such that the national identity is more easily ascribed to Asian Americans? Capitalizing on fluctuations in ethnic diversity across U.S. metropolitan areas, the aim of the present research was to test whether context ethnic diversity accounts for the propensity to differentially associate the American identity with Asian Americans and European Americans.

\section{Implicit American = White Effect}

Perceived foreignness is a critical dimension to shed light on forms of marginalization affecting Asian American communities (Zou \& Cheryan, 2017). For example, reliable relations between such stereotypical perceptions and anti-minority policy attitudes and behaviors have been documented (Huynh, Devos, \& Altman, 2015; Yogeeswaran \& Dasgupta, 2010). In addition, experiences of being denied the national identity have been linked to identity dynamics 
and mental health outcomes among Asian American individuals (Cheryan \& Monin, 2005; Huynh, Devos, \& Smalarz, 2011; Liang, Li, \& Kim, 2004; Wang, Minervino, \& Cheryan, 2012). In line with a substantial literature showing that intergroup biases often operate outside of conscious control (Yogeeswaran, Devos, \& Nash, 2016), studies relying on techniques developed to assess implicit social cognition have provided direct evidence for the notion that the American identity is less strongly associated with Asian Americans than with European Americans (Devos \& Banaji, 2005; Devos \& Heng, 2009; Nosek, Smyth, et al., 2007; Yogeeswaran \& Dasgupta, 2010). The term "implicit American = White effect" was coined to capture this phenomenon. Although ethnic stereotypes about American identity have been documented on both explicit measures and implicit techniques, it is important to note that, even when conscious knowledge contradicts stereotypes (e.g., "I know that Lucy Liu is American, and Kate Winslet is not"), implicit associations still point to an American = White linkage (Devos \& Banaji, 2005; Devos \& Ma, 2008).

The propensity to implicitly equate being American with being White is a robust effect that has been documented using a variety of implicit measures and when European Americans are compared to African, Asian, Latino, and even Native Americans (for reviews, see Devos \& Mohamed, 2014; Yogeeswaran \& Dasgupta, 2014). However, this effect is not displayed uniformly by everyone or under all circumstances. First, the effect varies as a function of perceivers' ethnicity and political orientation. More precisely, the implicit American $=$ White effect is stronger among European American respondents than among members of ethnic minorities (Devos \& Anderson, in press; Devos \& Banaji, 2005; Devos, Gavin, \& Quintana, 2010; Nosek, Smyth, et al., 2007) and among more self-identified conservatives than liberals (Crawford \& Bhatia, 2012; Devos \& Ma, 2013; Ma \& Devos, 2014; Nosek, Smyth, et al., 2007). 
Second, implicit ethnic-American associations are sensitive to a variety of micro-interventions such as exposing individuals to positive vs. negative ethnic group members (Rydell, Hamilton, \& Devos, 2010), practicing counter-stereotypic vs. stereotypic responses (Devos \& Heng, 2009), downplaying vs. highlighting the ethnicity (Devos \& Ma, 2008, 2013) or allegiances (Yogeeswaran, Dasgupta, Adelman, Eccleston, \& Parker, 2011; Yogeeswaran, Dasgupta, \& Gomez, 2012) of ethnic group members. In the present work, we switched the focus by examining the interconnections between socio-structural factors and the implicit American $=$ White effect, introducing a macro-level perspective (Payne, Vuletich, \& Lundberg, 2017; Yogeeswaran, Devos, \& Nash, 2016). More precisely, we examined whether the ethnic diversity of the context in which individuals are immersed might be a source of variation in the extent to which the American identity is implicitly associated with Asian Americans and European Americans.

\section{Context Ethnic Diversity and Implicit Ethnic-American Associations}

The relations between context ethnic diversity and ethnic relations are complex (Craig, Rucker, \& Richeson, 2018; Hewstone, 2015). To simplify, some findings indicate that ethnic diversity is associated with a sense of group threat and an erosion of trust (Dixon, 2006; Putnam, 2007), while others point to ethnic diversity being linked to opportunities for interethnic contact, prosocial behaviors, more tolerant social norms, more complex self-definitions, and less pronounced intergroup biases (Christ et al., 2014; Nai, Narayanan, Hernandez, \& Savani, 2018; Schmid, Hewstone, \& Al Ramiah, 2013). In some cases, distinct factors are sources of mitigating effects. For example, a cross-national comparison of the U.S. and Canada showed that negative effects of context ethnic diversity were reduced among individuals who had frequent contact with outgroup members (Stolle, Soroka, \& Johnston, 2008). In the same vein, a 
national survey in England showed that the direct negative effect of diversity on trust was counteracted by a positive indirect effect through contact and threat reduction (Schmid, Al Ramiah, \& Hewstone, 2014).

To our knowledge, only two studies examined the relations between context ethnic diversity and implicit intergroup biases. A pioneer study showed that larger proportions of Black residents in a state or county were associated with stronger implicit and explicit ingroup favoritism among White and Black respondents in the U.S. (Rae, Newheiser, \& Olson, 2015). More recently, weaker implicit stereotypic associations between weapons and Black Americans (relative to White Americans) were observed in multiethnic and integrated metropolitan areas (Sadler \& Devos, in press). Here, we extend research on this topic by examining a different interethnic comparison (Asian vs. European Americans instead of Black vs. White Americans). In addition, in contrast to the first study (Rae et al., 2015) and in line with the second study (Sadler \& Devos, in press), we focused on cognitive or semantic associations (i.e., beliefs or stereotypes) rather than on affective or evaluative responses (i.e., attitudes, ingroup favoritism, or prejudice). The ascription of the American identity to various ethnic groups reflects stereotypical associations that are distinct from more strictly evaluative responses (Ma \& Devos, 2014).

Implicit associations reflect knowledge shaped by the cultural milieu in which individuals are immersed (Devos, 2008; Olson, Fazio, \& Han, 2009; Rudman, 2004). Many socio-historical factors contribute to foster an implicit association between the American identity and whiteness: differences between ethnic groups in terms of social and numerical statuses, asymmetries of power, cultural products, and everyday experiences, contribute to produce and perpetuate the American $=$ White effect. From this perspective, stereotypes about American 
identity stem from highly accessible knowledge that pervades social environments. In a nutshell, this stereotype operates as a heuristic or default assumption: being American and being White are conflated and non-White ethnic groups, to various degrees, are excluded from the national identity. For example, Asian Americans might be perceived as perpetual foreigners because their Asian heritage is socio-culturally constructed as a relatively atypical characteristic (less expected, common, familiar, and in some cases valued) compared to European ancestry. Such stereotypical assumptions are based on a fairly simplistic or rigid representation of the American identity that goes hand in hand with dichotomous categorical thinking (e.g., White vs. Asian or majority vs. minority).

Examining the role of context ethnic diversity may provide some insights into the role that environments play in shaping ethnic-American associations. Accessible socio-cultural knowledge (e.g., prevalent cultural symbols, people in position of power, everyday social interactions) ought to differ across more or less diverse contexts. Compared to individuals reared in a homogenous and predominantly White environment, individuals immersed in an ethnically diverse setting may draw on knowledge that might influence their default or baseline assumption about who is prototypical of the American identity, as well as the complexity of their mental representation of the American identity. As a result, they may have an easier time linking the American identity to ethnic minorities, including Asian Americans. In other words, the characteristics of relatively local contexts (e.g., metropolitan area or neighborhood) may have some bearing on how individuals implicitly construe what it means to be American. The implicit definition of a national identity, a large-scale superordinate category, may be partially determined by knowledge and experiences occurring at a more local level. More precisely, the 
diversity of the more immediate context may make it easier or harder to automatically associate the American identity with various ethnic groups making up the U.S. population.

\section{Minority Representation, Variety, and Integration}

The bulk of the empirical literature has relied on fairly crude definitions and measures of ethnic diversity. More sophisticated conceptualizations and assessments of ethnic diversity may yield new theoretical insights and richer findings (Biemann \& Kearney, 2010; Budescu \& Budescu, 2012; Harrison \& Klein, 2007). In the present case, we sought to increase our understanding of the role of context ethnic diversity by simultaneously considering three dimensions of context ethnic diversity (see also, Sadler \& Devos, in press). Capitalizing on prior scientific contributions (Iceland, 2004; Koopmans \& Schaeffer, 2015; Massey \& Denton, 1988; Reardon \& Firebaugh, 2002; Schaeffer, 2013), we selected three distinct, yet complementary, dimensions of context diversity and speculated about the potential mechanisms through which each of them may account for variations in implicit ethnic-American associations.

The most common and simple conceptualization of context diversity is the relative presence of a particular minority ethnic group in a geographical area. Minority representation (MR) is the proportion of the population a specific ethnic group constitutes. For example, in the present research (focusing on a comparison between Asian Americans and European Americans), a metropolitan area would be higher in minority representation if the total population in this area includes $15 \%$ rather than $2 \%$ of Asian Americans. The relative presence of an ethnic minority group in a context, even if defined in a strictly numerical sense, may have some bearing on its socio-cultural salience. In line with evidence for accessibility effects in implicit stereotyping (Devos \& Heng, 2009; Payne, Jacoby, \& Lambert, 2005), when Asian Americans represent a significant segment of the local population, knowledge about this specific 
ethnic group maybe become more accessible and, as a result, be incorporated in baseline or default assumptions. The presence and visibility of Asian American individuals and cultures in the local milieu may be reflected in the socio-cultural construction of what it means to be American and, at least to some extent, translate into a greater inclusion of Asian Americans in the national identity. As minority representation increases across areas, Asian Americans might become more salient which could dilute stereotypic assumptions about who is American. Thus, our first hypothesis (H1) was that the implicit American = White effect would be weaker in areas with a relatively high proportion of Asian Americans.

An important limitation of minority representation is that it ignores the potential role of other ethnic minority groups (White, Kim, \& Glick, 2005). Variety (V) reflects the presence of multiple ethnic groups in an area. More precisely, variety captures the proportional equivalence of different ethnic groups in a context. For example, a metropolitan area with $60 \%$ Whites, $20 \%$ Asians, 10\% Latinos, and 10\% Blacks would have a higher variety score than one with $75 \%$ Whites, 20\% Asians, 3\% Latinos, and 2\% Blacks because the population is more evenly dispersed across ethnic groups in the former than latter case. In terms of minority representation, these two contexts are identical (in both cases Asians account for $20 \%$ of the population). Variety provides additional information about the diffusion of the remaining ethnic groups in an environment that may have implications for the social-cultural knowledge that individuals draw from when ascribing the American identity to various ethnic groups. First, keeping minority representation constant, any increase in variety would imply that European Americans represent a smaller fraction of the population and thus make minority groups more salient. Second, a context characterized by multiple ethnic groups may foster a more complex cognitive representation of the American identity. Moving away from dichotomous categorical thinking, 
the environment might be construed as a multiethnic entity. This mental mapping might transfer to the definition of the national identity: a White vs. non-White or majority vs. minority frame gives way to more fine-grained distinctions among multiple ethnic groups that might be conducive of inclusivity. This rationale is consistent with research showing that a more complex or diverse representation of the social environment is linked to less pronounced intergroup biases (Brauer \& Er-rafiy, 2011; Er-rafiy \& Brauer, 2012; Hartstone \& Augoustinos, 1995; Miller, Brewer, \& Arbuckle, 2009; Schmid et al., 2013; Waldzus, Mummendey, Wenzel, \& Weber, 2003; Waldzus, Mummendey, \& Wenzel, 2005). Our second hypothesis (H2) was that the implicit American $=$ White effect would be weaker in areas characterized by a relatively even representation of multiple ethnic groups.

Variety does not capture the extent to which ethnic groups live in integrated areas or enclaves (Koopmans \& Schaeffer, 2015). Integration (I) reflects the relative distribution of ethnic groups across smaller environments, such as neighborhoods within a metropolitan area. Integration distinguishes metropolitan areas in which ethnic groups coexist within versus live in disparate neighborhoods (Koopmans \& Schaeffer, 2015; Massey \& Denton, 1988). As discussed earlier, a metropolitan area composed of $60 \%$ Whites, $20 \%$ Asians, $10 \%$ Latinos, and 10\% Blacks would be relatively high on both the minority representation and variety dimensions. The distribution of these four groups across neighborhoods could be indicative of integration or segregation. If the distribution of ethnic groups at the metropolitan and neighborhood levels are isomorphic, the metropolitan area would be considered integrated. If, compared to their distribution at the metropolitan level, some ethnic groups are highly over-represented or underrepresented in some neighborhoods, the metropolitan area would be considered segregated. Integration is a characteristic of the metropolitan area, but it is based on variations in the 
distributions of ethnic groups across neighborhoods making up the metropolitan area. To put it more simply, if most members of a specific ethnic group tend to live in a particular subset of neighborhoods, whereas most members of another ethnic group tend to be located in other neighborhoods, we are dealing with ethnic enclaves. In contrast, if the distribution of the ethnic groups is even across neighborhoods and similar to that of the metropolitan area as a whole, the metropolitan area is integrated. The implications of the integration dimension for ethnicAmerican associations are not straightforward, but it is likely that integrated metropolitan areas offer greater opportunities for interethnic contact. Prior research already documents that living in a diverse neighborhood is associated with reduced intergroup biases and that the frequency of personal and positive contact with outgroup members is one of the underlying mechanisms (Christ et al., 2014; Schmid et al., 2014; Wagner, Hewstone, \& Machleit, 1989). In the present context, integration is likely to capture variability in the extent to which individuals are exposed to members of different ethnic backgrounds and to cultural symbols or practices associated with these ethnic groups. When the metropolitan area is integrated, diversity is experienced in a more proximal, repeated, and direct manner. In contrast, segregation implies a more distal, sporadic, and indirect exposure to diversity. We posit that integration is likely to increase the accessibility of socio-cultural knowledge that counteracts the prevalent American $=$ White effect and to foster a more complex representation of the American identity. The daily immersion in multicultural experiences may act as constant reminders that ethnic minorities are an integral part of the American identity and that the very fabric of this identity is complex and multifaceted, thereby diluting stereotypical expectations. This point is also consistent with research showing that more frequent multiethnic experiences are related to less stereotypic outgroup expectations (Tadmor, Hong, Chao, Wiruchnipawan, \& Wang, 2012). In contrast, segregated areas might reduce the 
likelihood that these mechanisms operate given that diversity is not endemic to the local context. Thus, integration might go hand in hand with greater inclusion of Asian Americans (and possibly other ethnic minority groups) in the national identity. Our third hypothesis (H3) was that the American = White effect would be weaker in relatively integrated areas .

\section{Research Overview}

Capitalizing on fluctuations in the demographic make-up of U.S. metropolitan areas, the goal of the present research was to systematically examine the relations between three dimensions of ethnic diversity (minority representation, variety, and integration) and implicit ethnic-American associations. We expected that each indicator of ethnic diversity would uniquely account for implicit ethnic-American associations assessed via an Implicit Association Test (IAT, Nosek, Greenwald, \& Banaji, 2007). More precisely, we predicted that greater ethnic diversity, whether operationalized as minority representation, variety, or integration, would be associated with a weaker implicit American $=$ White effect. The three hypotheses were formulated based on essentially two mechanisms through which context diversity might operate that can be succinctly restated. First, context diversity may affect the accessibility of knowledge about specific ethnic groups that is contributing to baseline or default assumptions about the prototypical American. Second, context diversity may broaden and complexify the representation of the national identity. The first mechanism is more likely to account for how minority representation operates (H1). Both mechanisms are likely to account for the effect of variety $(\mathrm{H} 2)$. Integration $(\mathrm{H} 3)$ is likely to affect the extent to which ethnic diversity is experienced in a proximal, repeated, and direct manner which may have an impact on the accessibility of knowledge about ethnic groups and the breath and complexity of the national identity. It is important to acknowledge that the data available did not allow us to provide direct 
evidence for the role of specific mechanisms. This limitation being noted, testing the unique contribution of three distinct indicators of context ethnic diversity is a useful step toward a better understanding of the role of context ethnic diversity in ethnic relations. In particular, the research question tackled here represents an attempt to highlight effects of socio-structural factors on implicit ethnic-American associations. Using a multi-level framework (see also MacInnis, Page-Gould, \& Hodson, 2017; Sadler \& Devos, in press), we sought to document reliable effects of context ethnic diversity (context-level predictors) on implicit associations controlling for the effects of socio-demographic variables such as ethnicity, age, gender, level of education, and political orientation (individual-level predictors). The present research is in line with an emerging body of work stressing that implicit associations cannot be reduced to intraindividual processes in that they are deeply interconnected with the socio-structural characteristics of the contexts in which individuals are immersed (Payne et al., 2017; Yogeeswaran et al. 2016). Identifying robust relations between socio-structural variables, including context diversity indicators, and implicit associations is an important step towards understanding the societal foundations and systemic implications of knowledge that operates outside of conscious control.

Given the paucity of research on the topic, formulating more complex predictions was challenging. Nonetheless, to provide some empirical foundations for future theorizing, we ran exploratory analyses testing interactions among the three indicators of context ethnic diversity (minority representation, variety, and integration). For example, the effect of variety or integration might be more determinant in metropolitan areas characterized by a relatively high proportion of Asian Americans. In addition, depending on the configuration of diversity indicators, some mechanisms discussed earlier might be more or less likely to operate. To 
explore these possibilities, we examined the extent to which the effect of each indicator of context ethnic diversity might be moderated by the other two.

As stated earlier, prior research documents that the implicit American $=$ White effect is more pronounced among European American respondents than among Asian American respondents (Devos \& Anderson, in press; Devos \& Banaji, 2005; Nosek, Smyth, et al., 2007). Given the focus of the present work and the availability of a sample including a large proportion of Asian American respondents (see Participants section), we explored whether the effects of diversity indicators might be moderated by respondents' ethnicity. The two ethnic groups contrasted here have particular significance for individuals who identify with the categories “Asian Americans" or "European Americans." In addition, the relative ethnic diversity of the context they are reared in may have different implications depending on whether individuals belong to an ethnic minority or majority group. Thus, it was important to test whether any effect of the context diversity indicators might be qualified by whether the respondents define themselves as Asian American or European American. The present work focused on implicit associations, but for comparison purpose analyses performed on an explicit measure of ethnicAmerican associations are reported in the supplemental material.

\section{Method}

\section{Participants}

Participants who completed the Asian-European American IAT on Project Implicit (https://implicit.harvard.edu) between 2004 until 2017 were included (Xu, Lofaro, Nosek, \& Greenwald, 2018). IATD scores were available for 507,456 participants. Of these, 16,151 (3.2\%) were dropped based on having $10 \%$ or more trial responses faster than $300 \mathrm{~ms}$ following standard practices (Greenwald, Nosek \& Banaji, 2003). Because participant demographic 
variables were controlled in analyses, only participants who reported age, race/ethnicity, gender, education attainment, and political orientation $(N=379,931)$ were included. Finally, participants must have reported a current zip code $(N=294,530)$, which must lie in a Metropolitan Statistical Area (MSA) with 50 or more participants. The final sample included 271,006 participants across 304 MSAs covering widely distinct U.S. regions. The median number of participants in an MSA was 3,955 (25th percentile $=893,75$ th percentile $=10,415$ and maximum $=20,347)$. Given use of extant data, a priori power analyses are moot. However, the number of MSAs included and the minimum number of participants per MSA were more than sufficient to allow requisite statistical power (Hox, 1998). These screening and selection criteria implied that participants included in the final sample provided valid data (no missing values) on all the variables introduced in the analyses.

Participants were 26.54 years old on average $(S D=11.16)$. The sample had more women than men (60.9\% female) and was composed of $44.8 \%$ Whites, $31.7 \%$ Asians, $4.0 \%$ Blacks, 3.4\% Latino/as, and 16.0\% who chose other ethno-racial categories. Sixty-nine percent of participants who were at least 25 years old obtained a bachelor's degree or more. Finally, participant political orientation varied but leaned slightly toward the liberal end of the spectrum ( $M=3.95$ on 1 to 6 -point scale used $2004-2006 ; M=4.67$ on 1 to 7 -point scale used 20062017). While very large, this dataset should not be mistaken as being representative of a definable population. There are selection influences that determine who learns of and visits the site, choice of tasks, and completing the measures.

\section{Procedure}

Participants completed the IAT, a short questionnaire, and a series of demographic questions. A description of all measures in this dataset is available at https://osf.io/cpmfk/. Only 
measures of interest to our specific research questions are described here. The aims and method of the present research were approved by the Institutional Review Board of our institution.

Implicit ethnic-American associations. The IAT assessed the direction and strength of the associations between the concepts "American" vs. "foreign" and two ethnic groups ("Asian American" vs. "European American"). Images of U.S. and foreign landmarks were used to represent the first pair of concepts and images of Asian and White faces (men and women) were used to represent the ethnic groups. Stimuli are available at https://osf.io/cpmfk/. In one block of trials, the concept "Asian American" was paired with "American" and the concept "European American" was paired with "foreign." In another block of trials, the concept "European American" was paired with "American" and the concept "Asian American" was paired with “foreign.” Participants were asked to sort each stimulus into its correct category as quickly as possible by pressing the appropriate key. When participants made an error, they were required to choose the correct answer to move on to the next trial. Each critical block included a total of 60 trials with a brief message appearing after the first 20 trials reminding participants to go fast.

Demographic questionnaire. Participants were asked to provide demographic information including age, gender, ethnicity, political orientation, education, and current zip code. Current zip code was used to determine residency in a specific MSA. The single-item measure used to assess political orientation was a 6-point scale ranging "strongly conservative" (coded 1) to "strongly liberal" (coded 6) until December 7, 2006; it was replaced after that by a 7-point scale ranging from "strongly conservative" (coded 1) to "strongly liberal" (coded 7), with the mid-point of the scale being labelled "neutral" (coded 4).

Context indicators. Information about context ethnic diversity for U.S. metropolitan areas was based exclusively on data from the 2010 U.S. Census Bureau (U.S. Census Bureau, 
2012a). Typically, MSAs have populations greater than 100,000 centered in a metropolitan area but including proximal areas that are integrated socially or economically. Census tracts are more local divisions that have stable boundaries across time and resident populations of a few thousand. The 2010 U.S. Census was conducted approximately mid-way through the IAT data collection (running from 2004 to 2017). Although, indicators of context diversity may fluctuate over time, variations across MSAs - the focus on the present research - are extremely stable over one decade.

Minority representation was calculated as the proportion of Asian Americans in an MSA $\left(\pi_{\mathrm{r}}\right)$.

Minority representation: $M R=\pi_{\mathrm{r}}$

Variety was calculated as an entropy score (Iceland, 2004) per MSA using Equation 2, where $r$ denotes ethnic groups. Higher scores on variety represent more even proportional representation of four major ethnic groups (African, Asian, European, and Latino Americans). In addition to calculating entropy scores per MSA, entropy scores for census tracts within MSA were calculated for use in integration scores.

Variety: $V=\sum_{r=1}^{r}\left(\pi_{r}\right) \ln \left[\frac{1}{\pi_{r}}\right]$

Integration was calculated from Equation 3, where $H$ is the multigroup Theil's $H$ or multigroup information theory index (Iceland, 2004), $V$ is the variety score per MSA, $T$ is the population of the MSA, $V_{i}$ is the variety score per census tract within each MSA, and $t_{i}$ is the population of the census tract $i$.

$$
\text { Integration: } I=1-H=1-\left(\sum_{i=1}^{n}\left[\frac{t_{i}\left(V-V_{i}\right)}{V * T}\right]\right)
$$


In the current sample, minority representation (proportion of Asian Americans) across MSAs averaged about $3 \%(M=3.15 \%, S D=6.10 \%)$ ranging from nearly $0 \%$ to $60 \%$. To account for non-normality, a natural log transformation was applied to minority representation in all analyses. Variety can range from 0 to 1.396 with four groups. On average, variety was near the midpoint of the scale $(M=0.68, S D=0.25)$ and showed considerable variability between MSAs. Integration, which compares the distribution of racial/ethnic groups within census tracts to that of the MSA, can range from 0 to 1 with higher numbers indicating that groups are distributed similarly at both levels. On average, integration was moderately high $(M=.83, S D=$ $.089)$.

Relationships among diversity measures were also examined. Minority representation was positively associated with variety $\left(r_{302}=.59, p<.001\right)$. As the proportion of Asian Americans increased, so did the extent to which ethnic groups were evenly distributed. Variety was negatively associated with integration $\left(r_{302}=-.45, p<.001\right)$. As groups were more evenly distributed at the MSA level, there was typically less integration from neighborhood to neighborhood. In contrast, there was no evidence that minority representation was related to integration $\left(r_{302}=.10, p=.069\right)$. Tolerances among the set of measures were also examined. Variance inflation factors were below 2 suggesting multicollinearity was not an issue.

\section{Results}

\section{Testing the Implicit American $=$ White Effect at the Individual and Context Levels}

IAT data were analyzed following the algorithm recommended by Greenwald et al. (2003). More precisely, the difference between the mean response latency for the two critical blocks of trials, divided by its associated standard deviation, was computed. This quotient was computed separately for the first 20 trials and the last 40 trials; the two values were then 
averaged. As recommended by Greenwald et al. (2003), statistical analyses were always performed on this index known as the IATD. In the present case, the IATD score reflects the extent to which the concept "American" (relative to "foreign") is more strongly associated with European Americans than with Asian Americans (i.e., American = White effect). On average across participants, the American $=$ White effect approached medium size $(M=0.287, S D=$ $0.463)$ and was significant, $t(271,005)=322.087, p<.001, R^{2}=.277$. Individual scores ranged from positive to negative. Across MSAs, the average IATD score was large and positive in all MSAs $(M=0.365, S D=0.068)$, and also significant, $t(303)=93.276, p<.001, R^{2}=.966$. In sum, the data suggest that Asian Americans are implicitly seen as less American than European Americans at the individual and context levels.

\section{Testing the Unique Contributions of Minority Representation, Variety, and Integration}

IATD scores were analyzed using multilevel models with participant as the Level 1 unit and MSA as the Level 2 unit (see Table 1). Although the Intraclass Correlation Coefficient value $(I C C=.018)$ was very small, a multilevel analytic approach was used because the theoretical questions of interest are the effects of context properties on individuals immersed within them (Luke, 2004). Rather than relying exclusively on significance testing, only findings with at least a small effect size $\left(r^{2} \geq .030\right)$ are discussed. Level 1 fixed effects were group-mean centered and Level 2 fixed effects were grand-mean centered (Enders \& Tofighi, 2007). Gender was contrastcoded (+1 if Male, -1 if Female). Participant ethnicity was coded in orthogonal codes: WvA (+1 if White, -1 if Asian, 0 if Other) and WAvO (+1 if White or Asian, -2 if Other). Finally, political orientation was z-scored separately for the 6-point and 7-point scale versions, then combined. Effect size estimates $\left(R^{2}\right)$ were calculated according to Snijders and Bosker (2012). 
The first model included individual-level socio-demographic predictors and context diversity predictors of implicit ethnic-American associations (Model 1). This model was significantly better than a model including only the individual-level predictors, $\chi^{2}(3)=23.918$, $p<.001$, explaining $8.8 \%$ of Level 1 variation. Although each of the demographic variables was significant, the effects were quite small, with the exception of participant ethnicity $\left(r^{2}=\right.$ .073). White participants showed a greater American $=$ White effect than did Asian participants.

Context diversity measures accounted for $52.0 \%$ of the Level 2 variation in implicit ethnic-American associations. As predicted, increases in minority representation $\left(\mathrm{H} 1, r^{2}=.338\right)$ and variety $\left(\mathrm{H} 2, r^{2}=.029\right)$ each uniquely predicted decreases in the American $=$ White effect, but the effect of variety was just below the $3.0 \%$ threshold. There was no evidence that implicit ethnic-American associations varied as a function of integration (H3).

\section{Testing for Interactions among Diversity Dimensions}

Next a model with two-way interactions among context diversity measures proved significantly better than Model $1, \chi^{2}(3)=34.300, p<.001$, explaining $8.8 \%$ of the remaining variation (Model 2). There was a significant interaction between minority representation and variety, $r^{2}=.036$ (see Figure 1). Simple effects tests (performed at one standard deviation above and below the mean) revealed that the negative relationship between minority representation and the American $=$ White effect was larger when the degree of variety was high, $B=-.064, t=-$ $14.259, p<.001$, than when it was low, $B=-.042, t=-7.213, p<.001$. Simple effects of variety were also tested. In areas with high minority representation, areas with higher variety were characterized by a less pronounced American $=$ White effect than areas with lower variety, $B=-$ $.063, t=-4.005, p<.001$. However, in areas with relatively low minority representation, there was no evidence that the magnitude of the American $=$ White effect varied as a function of 
variety, $B=-.005, t=-.261, p=.794$. The interaction between minority representation and integration was also significant, but it accounted for less than $3 \%$ of context-level variance.

\section{Testing the Moderating Effects of Participant Ethnicity}

Analyses were conducted to determine if the effects of the diversity of the environment differed between White vs. Asian participants (Model 3). Cross-level two-way and three-way interactions between context diversity measures and the WvA contrast code were added and the slope for WvA was allowed to be random. This model was significantly better than Model 2 (adding a random WvA slope), $\chi^{2}(3)=33.264, p<.001$, and explained $6.6 \%$ of the remaining variation. Although two interactions with the WvA contrast code and context diversity measures were significant, each accounted for less than 3.0\% of the Level 2 variation.

\section{Controlling for Additional Context Variables}

We also examined whether the effects of context diversity held over and above the effects of three socio-structural variables capturing important facets of metropolitan areas. The list of variables potentially confounded with context diversity indicators is long; we focused on three variables that might be particularly relevant to processes underlying implicit ethnicAmerican associations. We examined differences across MSAs in population density (average number of people per square mile), median annual household income, and percent of foreignborn persons (people who were not a U.S. citizen at birth). The first indicator was acquired from the 2010 U.S. Census (U.S. Census Bureau, 2012b) and the latter two were taken from the American Community Survey for 2012 that gives the average value for the prior five years (U.S. Census Bureau, 2014a; U.S. Census Bureau, 2014b). Population density, economic wealth, and presence of immigrant populations may influence the nature and frequency of daily experiences and interactions, as well as a range of social norms, beliefs, attitudes, and psycho-social 
dynamics. Controlling for these confounding variables should lend further support for the distinct role of context diversity. Overlap among these predictors was empirically substantiated. More densely populated MSAs were characterized by higher proportions of Asian residents $\left(r_{302}=.43, p<.001\right)$, more variety $\left(r_{302}=.43, p<.001\right)$, and less integration $\left(r_{302}=-.48, p<.001\right)$. Higher median incomes were observed in MSAs with higher minority representation $\left(r_{302}=.61\right.$, $p<.001)$ and variety $\left(r_{302}=.29, p<.001\right)$. Higher proportions of foreign-born residents also characterized MSAs with higher proportions of Asian residents $\left(r_{302}=.61, p<.001\right)$, more variety $\left(r_{302}=.60, p<.001\right)$, and less integration $\left(r_{302}=-.15, p=.008\right)$. Thus, Model 2 was reestimated controlling for these three variables. This model was a significantly better fit than Model $2, \chi^{2}(3)=44.889$, explaining $1.1 \%$ of the additional Level 2 variation. There was no evidence that population density or median income was related to the American $=$ White effect. The percentage of foreign-born persons accounted for most of the improvement in fit explaining $9.3 \%$ of the variation, $B=-.361, t=-6.743, p<.001$. As there were more foreign-born persons across MSAs, implicit ethnic-American associations became more inclusive. In terms of context diversity, the relationship between minority representation and ethnic-American associations persisted and was not explained away by these additional characteristics of MSAs. Interestingly, the effect of variety and the interaction between minority representation and variety found in Models 2 and 3 were non-significant in this model. Although the contribution of the proportion of foreign-born people is not fully understood, it is worth stressing the direction of the effects. To put it simply, higher proportions of foreign-born people were associated with a more inclusive national identity. This finding is consistent with the notion that this characteristic is indicative of multiethnic communities or settings and is not consistent with the idea that the 
presence of foreign-born populations might perpetuate or exacerbate the dominant American $=$ White assumption.

\section{Discussion}

The present research documents reliable relations between context ethnic diversity and implicit ethnic-American associations. The conceptualization of context ethnic diversity as encompassing distinct facets (minority representation, variety, and integration) is useful in that two out of three indicators are sources of reliable (simple or interactive) effects on the task examined in this study. As hypothesized, minority representation (H1) is associated with weaker implicit American = White effect. The role of variety is more complex than anticipated $(\mathrm{H} 2)$. More precisely, the effect of variety is qualified by the level of minority representation. Variety is associated with a greater inclusion of Asian Americans when this group represents a relatively high proportion of the local population. When minority representation is relatively low, the presence of additional ethnic minority groups does not make much of a difference. In retrospect, this interaction is not very surprising. Variety may contribute to a more inclusive definition of the American identity, but it may not have much influence on the perceptions of ethnic groups that represent small portions of the overall population. The multiethnic milieu may contribute to a greater inclusion of ethnic groups that are relatively salient in the context. In contrast to what we predicted (H3), integration does not account for implicit ethnic-American associations.

Building on prior contributions (Iceland, 2004; Koopmans \& Schaeffer, 2015; Massey \& Denton, 1988; Reardon \& Firebaugh, 2002; Schaeffer, 2013), considering simultaneously the independent and interactive contributions of three distinct facets of context ethnic diversity allows us to map out a wide range of ethnic diversity configurations and to examine how they relate to implicit associations between ethnic groups and the American identity. Prior 
psychosocial research on the correlates of context ethnic diversity has relied on fairly simplistic conceptualizations of this construct with minority representation being the most common and often sole indicator. The present findings do not resolve inconsistencies in the literature (Hewstone, 2015; Putnam, 2007), but they do underscore the value of a multi-dimensional perspective on context ethnic diversity.

To justify our hypotheses, we discussed various mechanisms that could account for the impact of context ethnic diversity on implicit ethnic-American associations. Given that measures that could potentially shed light on mediating factors were not available in the dataset, much remains to be learned on that front. In line with the complex picture emerging from the literature (Craig et al., 2018; Hewstone, 2015), there are probably multiple underlying mechanisms coming into play and these are not well understood yet. The effects obtained are consistent with the general idea that the extent to which individuals implicitly associate the American identity with Asian Americans and European Americans is a function of the diversity of the context they are immersed in. Over and above variations linked to the socio-demographic characteristics of respondents, the larger the proportion of Asian Americans (minority representation) and the more the milieu can be characterized as multiethnic (variety), the less individuals are likely to display the American $=$ White effect. Minority representation and variety may both have an influence on the socio-cultural knowledge that individuals draw upon. Baseline or default assumptions about who is American may differ as a function of the ethnic make-up of the metropolitan area in which individuals reside. A low proportion of Asian Americans or a low representation of ethnic minorities more broadly may foster and perpetuate the dominant American $=$ White effect. In contrast when people of Asian descent represent a more substantial segment of the local population and multiple ethnic groups are more evenly represented, Asian 
Americans can more easily be included in the American identity. As such these findings provide a large-scale illustration of accessibility effects in implicit stereotyping previously documented in experimental studies (Devos \& Heng, 2009; Payne et al., 2005). Not only does the context make more accessible knowledge that reflects the presence and contributions of Asian Americans, it may also lead to a more complex representation of the American identity recognizing the presence and the role of multiple ethnic minority groups. These effects may help dilute the perpetual foreigner stereotype. This explanatory principle fits with prior research showing that inducing a more complex or diverse representation of a superordinate identity reduced intergroup biases (Waldzus et al., 2003, 2005).

The effects of context diversity may raise questions regarding the extent to which implicit associations map on to what individuals observe and experience in their immediate environment. The present findings do not speak directly to the relative accuracy of stereotypes (Jussim, Cain, Crawford, Harber, \& Cohen, 2009). Doing so would require calibrating and comparing implicit associations to an objective frame of reference. More to the point, the present findings document that implicit associations about who is American reflect characteristics of the context in which individuals are immersed. In that sense, they stem from daily experiences constrained by the ethnic make-up of the environment.

In contrast to what we predicted, integration is not a source of meaningful variation in implicit ethnic-American associations. It is possible that this more complex computation of the ethnic make-up of metropolitan areas (taking into account not only the presence of multiple ethnic groups, but also their distributions across neighborhoods) does not have any bearing on implicit ethnic-American associations. It is also possible that integration is the source of relatively complex effects pulling in opposite directions. In integrated metropolitan areas, the 
more proximal experiences of diversity may be associated with firsthand exposure to diverse individuals, but these settings may also activate various threat responses that may stem from the perception that ethnic groups compete for the same resources and opportunities or from a sense of uncertainty associated with greater complexity and heterogeneity in norms and values (Dixon, 2006; Putnam, 2007). In addition, the two mechanisms through which context diversity might be operating may not necessarily be facilitated in relatively integrated settings. In fact, the accessibility and visibility of Asian Americans and the complex and multiethnic make-up of the metropolitan population might become less salient as integration increases. Thus, the potential benefits of contact with Asian Americans that might characterize integrated settings can be mitigated by the fact that integration implies a dispersion of Asian Americans throughout the metropolitan area. This possibility warrants further attention in light of research showing positive context effects of intergroup contact (Christ et al., 2014; MacInnis et al., 2017).

As shown in prior research (Christ et al., 2014; Dixon, 2006; Nai et al., 2018; Putnam, 2007; Schmid et al., 2013, 2014; Stolle, Soroka, \& Johnston, 2008), the relations between context ethnic diversity and important aspects of ethnic relations are relatively complex. Here, this point is substantiated by the fact that diversity indicators are not only sources of main effects, they also interact with one another. These new findings may pave the way for a firmer theoretical framework on the effects of context ethnic diversity. The present work is also innovative in that the research questions were examined in the realm of implicit stereotypes about American identity. Only two other studies reported relations between context ethnic diversity and implicit intergroup biases (Rae et al., 2015; Sadler \& Devos, in press). The three studies relied on datasets available through Project Implicit and combined them with ethnic diversity indicators derived from U.S. Census data. Interestingly, findings differ drastically 
across studies. Rae et al. (2015) used a single indicator of ethnic diversity (ratio of Black to White residents) that is most similar to minority representation. This indicator was associated with stronger implicit ingroup favoritism among both White and Black respondents. As was the case here, Sadler and Devos (in press) assessed three indicators of ethnic diversity and found that variety and integration (but not minority representation) were associated with weaker implicit Black-weapon stereotypes. In the present study, minority representation and variety are sources of reliable effects, but integration is not associated with weaker implicit American $=$ White effects.

It is challenging to isolate the factors that may account for these contrasting outcomes. Indicators of ethnic diversity were not the same across studies. In the present study the target ethnic groups were different and the focus was on associations with the American identity. Rae et al. (2015) examined variations across states and counties using aggregated data, whereas the other two studies focused on variations across metropolitan areas and relied on multilevel modeling techniques. Some of these differences might be more promising than others to shed light on apparently opposite findings. Behind these differences lurk important theoretical and empirical questions. Two speculative propositions are worth considering. First, implicit associations that are more evaluative in nature (i.e., racial prejudice IAT used in Rae et al. [2015]) may be more likely to reveal effects consistent with the notion that context diversity exacerbates intergroup biases, while more semantic implicit associations (i.e., ethnic stereotypes IATs such as those used here and in Sadler \& Devos [in press]) may be more likely to show evidence for diversity weakening stereotypical responses. For short, threat responses associated with context diversity are more likely to shape evaluative responses. Second, the fact that minority representation is associated with weakened American $=$ White associations, but does 
not account to Black-weapon associations, may be due to an important specificity of ethnicAmerican associations. This stereotype captures the extent to which various subgroups (defined based on ethnicity) are seen as more or less prototypical of a superordinate category (defined on the basis of national identity). The relative numerical representation of subgroups may inform the definition of the prototypical American. Minority representation in isolation is less likely to be the basis of association between ethnicity and danger or threat (Black-weapon stereotype). Future research is needed to unpack both context factors and implicit intergroup biases and to systematically examine their relations. For now, suffice to stress that ethnic diversity can be associated with either stronger (Rae et al., 2015) or weaker (Sadler \& Devos, in press; present findings) implicit intergroup biases. Thus, the picture emerging echoes that of the broader literature (Craig et al., 2018; Hewstone, 2015).

Several limitations of the present research need to be acknowledged. The findings reported here are purely correlational and, as such, do not speak to the causal impact of context ethnic diversity on implicit associations. In addition, it is not possible to determine whether minority representation or variety are associated with an increase of the Americanness of Asian Americans or a decrease of the Americanness of European Americans. The IAT captures the direction and strength of associations between two pairs of concepts. Given the structure of the task (Nosek, Greenwald \& Banaji, 2007), it yields an assessment of associative strengths that is inherently relative. On a related note, the comparison between Asian Americans and European Americans is leaving out important segments of the U.S. population. This choice was dictated by the fact that no analogous datasets are available for ethnic groups such as Latino or African Americans. It should be noted that these two ethnic groups were included in the computation of ethnic variety and integration. Future research should widen the scope of investigation not only 
by examining implicit associations about other ethnic minority groups, but also by incorporating the multiethnic nature of contexts. From a theoretical standpoint, the mechanisms through which context diversity operate are likely to yield similar effects for other minority groups (such as the broadening or complexification of the American identity). At the same time, distinct mechanisms may come into play for different interethnic comparisons (Zou \& Cheryan, 2017). Thus, further empirical evidence is needed before the present findings can be generalized to other ethnic minority groups.

Another important limitation pertains to the non-representativeness of the sample. Although the sample was relatively diverse and allowed us to control for the effects of important socio-demographic variables, the fact that it was not representative of the U.S. population limits our ability to generalize the findings. This being said, this issue was not central to our goal; even if respondents were not representative of a given population, meaningful contextual fluctuations were picked up in the analyses. It should also be noted that there was only tenuous evidence for the moderating role of respondents' ethnicity. We replicated the main effect of participants' ethnicity (with Asian American respondents showing a weaker implicit American = White effect than European American respondents; see also Devos \& Anderson, in press; Devos \& Banaji, 2005; Nosek, Smyth, et al., 2007), but this variable did not moderate the effect of the diversity dimensions.

To conclude, the present research suggests that one's understanding of who is an American is in part a function of immersion in local contexts. Within a country or nation, people's implicit associations between ethnic groups and the American identity may be linked to socio-structural characteristics of the local context they are living in. U.S. metropolitan areas cover a wide spectrum of ethnic diversity configurations (Farrell \& Lee, 2011; Iceland, 2004, 
2009). Some areas can be characterized as highly homogenous in the sense that the population is mostly comprised of individuals who belong to one specific ethnic group. Other areas can be more ethnically diverse in that the ethnic majority group and a relatively large minority group make up most of the population. Ethnic diversity can also reflect a greater variety of ethnic groups, each representing a significant proportion of the local population. Furthermore, diversity may capture contexts characterized by a relative integration of multiple ethnic groups and, as such, be contrasted to more segregated contexts. The plurality of ethnic representations across metropolitan areas provided a unique testing ground to examine important questions regarding the interconnections between context ethnic diversity and the extent to which the American identity is associated with two distinct ethnic groups. The data provide further evidence for the notion that Asian Americans are conceived of as perpetual foreigners in the U.S. (see also Armenta et al., 2013; Lee et al., 2009; Sue et al., 2007; Zou \& Cheryan, 2017), but they also nuance the picture by revealing important variations across contexts. More diverse metropolitan areas, in the sense that they include a larger portion of Asian Americans (minority representation) and include multiple ethnic groups besides Asian and European Americans (variety), are characterized by a greater implicit inclusion of Asian Americans in the national identity. 


\section{References}

Armenta, B. E., Lee, R. M., Pituc, S. T., Jung, K.-R., Park, I. J. K., Soto, J. A., . . Schwartz, S. J. (2013). Where are you from? A validation of the foreigner objectification scale and the psychological correlates of foreigner objectification among Asian Americans and Latinos. Cultural Diversity and Ethnic Minority Psychology, 19(2), 131-142. doi:10.1037/a0031547

Biemann, T., \& Kearney, E. (2010). Size does matter: How varying group sizes in a sample affect the most common measures of group diversity. Organizational Research Methods, 13(3), 582-599.

Brauer, M., \& Er-rafiy, A. (2011). Increasing perceived variability reduces prejudice and discrimination. Journal of Experimental Social Psychology, 47(5), 871-881. doi:10.1016/j.jesp.2011.03.003

Budescu, D. V., \& Budescu, M. (2012). How to measure diversity when you must. Psychological Methods, 17(2), 215-227. doi:10.1037/a0027129

Carlston, D. (2010). Models of implicit and explicit mental representation. In B. Gawronski \& B. K. Payne (Eds.), Handbook of implicit social cognition: Measurement, theory, and applications (pp. 38-61). New York, NY: Guilford Press.

Cheryan, S., \& Monin, B. (2005). 'Where are you really from?': Asian Americans and identity denial. Journal of Personality and Social Psychology, 89(5), 717-730. doi:10.1037/0022-3514.89.5.717

Christ, O., Schmid, K., Lolliot, S., Swart, H., Stolle, D., Tausch, N., .. Hewstone, M. (2014). Context effect of positive intergroup contact on outgroup prejudice. PNAS Proceedings 
of the National Academy of Sciences of the United States of America, 111(11), 39964000. doi:10.1073/pnas.1320901111

Craig, M. A., Rucker, J. M., \& Richeson, J. A. (2018). The pitfalls and promise of increasing racial diversity: Threat, contact, and race relations in the 21 st century. Current Directions in Psychological Science, 27(3), 188-193. doi:10.1177/0963721417727860

Crawford, J. T., \& Bhatia, A., (2012). Birther nation: Political conservatism is associated with explicit and implicit beliefs that President Barack Obama is foreign. Analyses of Social Issues and Public Policy, 12(1), 364-376: doi:10.1111/j.1530-2415.2011.01279.x

Devos, T. (2008). Implicit attitudes 101: Theoretical and empirical insights. In W. D. Crano \& R. Prislin (Eds.), Attitudes and attitude change (pp. 61-84). New York, NY: Psychology Press.

Devos, T., \& Anderson, K. J. (in press). Are we in or are we out? Ingroup prototypicality effects in implicit ethnic-American associations. Japanese Psychological Research.

Devos, T., \& Banaji, M. R. (2005). American = White? Journal of Personality and Social Psychology, 88(3), 447-466. doi:10.1037/0022-3514.88.3.447

Devos, T., \& Heng, L. (2009). Whites are granted the American identity more swiftly than Asians: Disentangling the role of automatic and controlled processes. Social Psychology, 40(4), 192-201. doi:10.1027/1864-9335.40.4.192

Devos, T., \& Ma, D. S. (2008). Is Kate Winslet more American than Lucy Liu? The impact of construal processes on the implicit ascription of a national identity. British Journal of Social Psychology, 47(2), 191-215. doi:10.1348/014466607x224521 
Devos, T., \& Ma, D. S. (2013). How 'American' is Barack Obama? The role of national identity in a historic bid for the White House. Journal of Applied Social Psychology, 43(1), 214226. doi:10.1111/jasp.12069

Devos, T., \& Mohamed, H. (2014). Shades of American identity: Implicit relations between ethnic and national identities. Social and Personality Psychology Compass, 8(12), 739754. doi:10.1111/spc3.12149

Devos, T., Gavin, K., \& Quintana, F. J. (2010). Say “adios” to the American dream? The interplay between ethnic and national identity among Latino and Caucasian Americans. Cultural Diversity and Ethnic Minority Psychology, 16(1), 37-49. doi:10.1037/a0015868

Dixon, J. C. (2006). The ties that bind and those that don't: Toward reconciling group threat and contact theories of prejudice. Social Forces, 84(4), 2179-2204. doi:10.1353/sof.2006.0085

Enders, C. K., \& Tofighi, D. (2007). Centering predictor variables in cross-sectional multilevel models: A new look at an old issue. Psychological Methods, 12(2), 121-138. doi:10.1037/1082-989X.12.2.121

Er-rafiy, A., \& Brauer, M. (2012). Increasing perceived variability reduces prejudice and discrimination: Theory and application. Social and Personality Psychology Compass, 6(12), 920-935. doi: 10.1111/spc3.12000

Farrell, C. R., \& Lee, B. A. (2011). Racial diversity and change in metropolitan neighborhoods. Social Science Research, 40(4), 1108-1123. doi:10.1016/j.ssresearch.2011.04.003 
Greenwald, A. G., Nosek, B. A., \& Banaji, M. R. (2003). Understanding and using the Implicit Association Test: 1. An improved scoring algorithm. Journal of Personality and Social Psychology, 85(2), 197-216. doi: 10.1037/0022-3514.85.2.197

Harrison, D. A., \& Klein, K. J. (2007). What's the difference? Diversity constructs as separation, variety, or disparity in organizations. The Academy of Management Review, 32(4), 11991228. doi:10.2307/20159363

Hartstone, M., \& Augoustinos, M. (1995). The minimal group paradigm: Categorization into two versus three groups. European Journal of Social Psychology, 25(2), 179-193. doi:10.1002/ejsp.2420250205

Hewstone, M. (2015). Consequences of diversity for social cohesion and prejudice: The missing dimension of intergroup contact. Journal of Social Issues, 71(2), 417-438. doi:10.1111/josi.12120

Hofmann, W., Gawronski, B., Gschwendner, T., Le, H., \& Schmitt, M. (2005). A meta-analysis on the correlation between the Implicit Association Test and explicit self-report measures. Personality and Social Psychology Bulletin, 31(10), 1369-1385. doi:10.1177/0146167205275613

Hox, J. J. (1998). Multilevel modeling: When and why. In I. Balderjahn, R. Mathar, \& M. Schader (Eds.), Classification, data analysis, and data highways (pp. 147-154). New York: Springer-Verlag.

Huynh, Q. L., Devos, T., \& Altman, H. R. (2015). Boundaries of American identity: Relations between ethnic group prototypicality and policy attitudes. Political Psychology, 36(4), 449-468. doi:10.1111/pops.12189 
Huynh, Q.-L., Devos, T., \& Smalarz, L. (2011). Perpetual foreigner in one's own land: Potential implications for identity and psychological adjustment. Journal of Social and Clinical Psychology, 30(2), 133-162. doi:10.1521/jscp.2011.3.2.133

Iceland, J. (2004). Beyond Black and White: Metropolitan residential segregation in multiethnic America. Social Science Research, 33(2), 248-271. doi:10.1016/S0049089X(03)00056-5

Iceland, J. (2009). Where we live now: Immigration and race in the United States. Berkeley: University of California Press.

Jussim, L., Cain, T. R., Crawford, J. T., Harber, K., \& Cohen, F. (2009). The unbearable accuracy of stereotypes. In T. D. Nelson (Ed.), Handbook of prejudice, stereotyping, and discrimination (pp. 199-227). New York: Psychology Press.

Koopmans, R., \& Schaeffer, M. (2015). Relational diversity and neighbourhood cohesion: Unpacking variety, balance and in-group size. Social Science Research, 53, 162-176. doi:10.1016/j.ssresearch.2015.05.010

Lee, B. A., Iceland, J., \& Farrell (2014). Is ethnoracial residential integration on the rise? Evidence from metropolitan and micropolitan America since 1980. In J. R. Logan (Ed.). Diversity and disparities: America enters a new century (pp. 415-456). New York: Russell Sage Foundation.

Lee, J., \& Bean, F. D. (2010). The diversity paradox: Immigration and the color line in twentyfirst century America. New York: Russell Sage Foundation.

Lee, S. J., Wong, N.-W. A., \& Alvarez, A. N. (2009). The model minority and the perpetual foreigner: Stereotypes of Asian Americans. In N. Tewari \& A. N. Alvarez (Eds.), Asian 
American psychology: Current perspectives (pp. 69-84). New York: Routledge/Taylor \& Francis Group.

Liang, C. T. H., Li, L. C., \& Kim, B. S. K. (2004). The Asian American racism-related stress inventory: Development, factor analysis, reliability, and validity. Journal of Counseling Psychology, 51(1), 103-114. doi:10.1037/0022-0167.51.1.103

Luke, D. (2004). Multilevel modeling (Quantitative applications in the social sciences 07-143). Thousand Oaks, CA: Sage.

Ma, D. S., \& Devos, T. (2014). Every heart beats true, for the Red, White, and blue: National identity predicts voter support. Analyses of Social Issues and Public Policy (ASAP), 14(1), 22-45. doi:10.1111/asap.12025

Massey, D. S., \& Denton, N. A. (1988). The dimensions of residential segregation. Social Forces, 67(2), 281-315.

MacInnis, C. C., Page-Gould, E., \& Hodson, G. (2017). Multilevel intergroup contact and antigay prejudice (explicit and implicit): Evidence of contextual contact benefits in a less visible group domain. Social Psychological and Personality Science, 8(3), 243-251. doi:10.1177/1948550616671405

Miller, K. P., Brewer, M. B., \& Arbuckle, N. L. (2009). Social identity complexity: Its correlates and antecedents. Group Processes \& Intergroup Relations, 12(1), 79-94. doi: $10.1177 / 1368430208098778$ 
Nai, J., Narayanan, J., Hernandez, I., \& Savani, K. (2018). People in more racially diverse neighborhoods are more prosocial. Journal of Personality and Social Psychology, 114(4), 497-515. doi:10.1037/pspa0000103

Nosek, B. A. (2007). Implicit-explicit relations. Current Directions in Psychological Science, 16(2), 65-69. doi:10.1111/j.1467-8721.2007.00477.x

Nosek, B. A., Greenwald, A. G., \& Banaji, M. R. (2007). The implicit association test at age 7: A methodological and conceptual review. In J. A. Bargh (Ed.), Social psychology and the unconscious: The automaticity of higher mental processes (pp. 265-292). New York, NY US: Psychology Press.

Nosek, B. A., Smyth, F. L., Hansen, J. J., Devos, T., Lindner, N. M., Ranganath, K. A., , . . Banaji, M. R. (2007). Pervasiveness and correlates of implicit attitudes and stereotypes. European Review of Social Psychology, 18(1), 36-88. doi: $10.1080 / 10463280701489053$

Olson, M. A., Fazio, R. H., \& Han, H. A. (2009). Conceptualizing personal and extrapersonal associations. Social and Personality Psychology Compass, 3(2), 152-170. doi:10.1111/j.1751-9004.2008.00164.x

Payne, B. K., Jacoby, L. L., \& Lambert, A. J. (2005). Attitudes as accessibility bias: Dissociating automatic and controlled processes. In R. R. Hassin, J. S. Uleman, \& J. A. Bargh (Eds.), The new unconscious (pp. 393-420). New York, NY: Oxford University Press.

Payne, B. K., Vuletich, H. A., \& Lundberg, K. B. (2017). The bias of crowds: How implicit bias bridges personal and systemic prejudice. Psychological Inquiry, 28(4), 233-248. 
doi:10.1080/1047840X.2017.1335568

Putnam, R. D. (2007). E pluribus unum: Diversity and community in the twenty-first century the 2006 Johan Skytte prize lecture. Scandinavian Political Studies, 30(2), 137-174. doi:10.1111/j.1467-9477.2007.00176.x

Rae, J. R., Newheiser, A.-K., \& Olson, K. R. (2015). Exposure to racial out-groups and implicit race bias in the United States. Social Psychological and Personality Science, 6(5), 535543. doi:10.1177/1948550614567357

Reardon, S. F., \& Firebaugh, G. (2002). Measures of multigroup segregation. Sociological Methodology, 32, 33-67.

Rudman, L. A. (2004). Sources of implicit attitudes. Current Directions in Psychological Science, 13(2), 79-82. doi:10.1111/j.0963-7214.2004.00279.x

Rydell, R. J., Hamilton, D. L., \& Devos, T. (2010). Now they are American, now they are not: Valence as a determinant of the inclusion of African Americans in the American identity. Social Cognition, 28(2), 161-179. doi:10.1521/soco.2010.28.2.161

Sadler, M., \& Devos, T. (in press). Ethnic diversity matters: Putting implicit associations between weapons and ethnicity in context. Group Processes and Intergroup Relations.

Schaeffer, M. (2013). Can competing diversity indices inform us about why ethnic diversity erodes social cohesion? A test of five diversity indices in Germany. Social Science Research, 42(3), 755-774. doi:10.1016/j.ssresearch.2012.12.018 
Schmid, K., Al Ramiah, A., \& Hewstone, M. (2014). Neighborhood ethnic diversity and trust: The role of intergroup contact and perceived threat. Psychological Science, 25(3), 665674. doi:10.1177/0956797613508956

Schmid, K., Hewstone, M., \& Al Ramiah, A. (2013). Neighborhood diversity and social identity complexity: Implications for intergroup relations. Social Psychological and Personality Science, 4(2), 135-142. 10.1177/1948550612446972

Snijders, T. A. B., \& Bosker, R. J. (2012). Multilevel analysis: An introduction to basic and advanced multilevel modeling ( $2^{\text {nd }}$ ed.). Los Angeles, CA: Sage.

Stolle, D., Soroka, S., \& Johnston, R. (2008). When does diversity erode trust? Neighborhood diversity, interpersonal trust and the mediating effect of social interactions. Political Studies, 56(1), 57-75. doi:10.1111/j.1467-9248.2007.00717.x

Sue, D. W., Bucceri, J., Lin, A. I., Nadal, K. L., \& Torino, G. C. (2007). Racial microaggressions and the Asian American experience. Cultural Diversity and Ethnic Minority Psychology, 13(1), 72-81. doi:10.1037/1099-9809.13.1.72

Tadmor, C. T., Hong, Y.-y., Chao, M. M., Wiruchnipawan, F., \& Wang, W. (2012). Multicultural experiences reduce intergroup bias through epistemic unfreezing. Journal of Personality and Social Psychology, 103(5), 750-772. doi:10.1037/a0029719

U.S. Census Bureau (2012a). SF1 100\%, Table P9, Hispanic or Latino, and Not Hispanic or Latino by Race. Retrieved from [https://factfinder.census.gov/faces/nav/jsf/pages/download_center.xhtml\#none].

U.S. Census Bureau (2012b). Population, Housing Units, Area, and Density: 2010 - United States -- Metropolitan Statistical Area. Retrieved from 
[http://factfinder.census.gov/faces/tableservices/jsf/pages/productview.xhtml?pid=DEC 10_SF1_GCTPH1.US24PR\&prodType=table].

U.S. Census Bureau (2014a). Median income in the past 12 months (in 2012 inflation-adjusted dollars) 2008-2012: American Community Survey 5-Year Estimates. Retrieved from [https://factfinder.census.gov/faces/tableservices/jsf/pages/productview.xhtml?pid=ACS _12_5YR_S1903\&prodType=table].

U.S. Census Bureau (2014b). Place of birth by nativity and citizenship status - Total population 2008-2012: American Community Survey 5-Year Estimates. Retrieved from [https://factfinder.census.gov/faces/tableservices/jsf/pages/productview.xhtml?pid=ACS _12_5YR_B05002\&prodType=table].

Wagner, U., Hewstone, M., \& Machleit, U. (1989). Contact and prejudice between Germans and Turks: A correlational study. Human Relations, 42(7), 561-574. doi:10.1177/001872678904200701

Waldzus, S., Mummendey, A., \& Wenzel, M. (2005). When 'different' means 'worse': In-group prototypicality in changing intergroup contexts. Journal of Experimental Social Psychology, 41(1), 76-83. doi:10.1016/j.jesp.2004.05.006

Waldzus, S., Mummendey, A., Wenzel, M., \& Weber, U. (2003). Towards tolerance: Representations of superordinate categories and perceived ingroup prototypicality. Journal of Experimental Social Psychology, 39(1), 31-47.

Wang, J., Minervino, C., \& Cheryan, S. (2012). Generational differences in vulnerability to identity denial: The role of group identification. Group Processes \& Intergroup Relations, 16(5), 601-617. doi:10.1177/136843021246196 
White, M., Kim, A. H., \& Glick, J. E. (2005). Mapping social distance: Ethnic residential segregation in a multiethnic metro. Sociological Methods \& Research, 34(2), 173-203. doi: $10.1177 / 0049124105280198$

Xu, K., Lofaro, N., Nosek, B. A., \& Greenwald, A. G. (2018). Asian American IAT 2004-2017. Retrieved from osf.io/cpmfk

Yogeeswaran, K., \& Dasgupta, N. (2010). Will the "real" American please stand up? The effect of implicit national prototypes on discriminatory behavior and judgments. Personality and Social Psychology Bulletin, 36(10), 1332-1345. doi:10.1177/0146167210380928

Yogeeswaran, K., \& Dasgupta, N. (2014). Conceptions of national identity in a globalised world: Antecedents and consequences. European Review of Social Psychology, 25(1), 189-227. doi:10.1080/10463283.2014.972081

Yogeeswaran, K., Dasgupta, N., \& Gomez, C. (2012). A new American dilemma? The effect of ethnic identification and public service on the national inclusion of ethnic minorities. European Journal of Social Psychology, 42(6), 691-705. doi:10.1002/ejsp.1894.

Yogeeswaran, K., Dasgupta, N., Adelman, L., Eccleston, A., \& Parker, M. T. (2011). To be or not to be (ethnic): Public vs. Private expressions of ethnic identification differentially impact national inclusion of White and non-White groups. Journal of Experimental Social Psychology, 47(5), 908-914. doi:10.1016/j.jesp.2011.03.010

Yogeeswaran, K., Devos, T., \& Nash, K. (2016). Understanding the nature, measurement, and utility of implicit intergroup biases. In C. G. Sibley \& F. K. Barlow 
(Eds.), Cambridge handbook of the psychology of prejudice (pp. 241-266). Cambridge, UK: Cambridge University Press.

Zou, L. X., \& Cheryan, S. (2017). Two axes of subordination: A new model of racial position. Journal of Personality and Social Psychology, 112(5), 696-717.

doi:10.1037/pspa0000080 
Table 1

Implicit Ethnic-American Associations as a Function of Context Diversity Dimensions.

\begin{tabular}{|c|c|c|c|c|c|c|c|c|c|}
\hline & & Model 1 & & & Model 2 & & & Model 3 & \\
\hline & $B$ & $t$ & $p$ & $B$ & $t$ & $p$ & $B$ & $t$ & $p$ \\
\hline \multicolumn{10}{|l|}{ Level 1} \\
\hline Intercept & .365 & 135.492 & $<.001$ & .368 & 119.751 & $<.001$ & .368 & 119.651 & $<.001$ \\
\hline Age & .003 & 29.886 & $<.001$ & .003 & 29.886 & $<.001$ & .003 & 29.782 & $<.001$ \\
\hline Gender & .011 & 12.554 & $<.001$ & .011 & 12.554 & $<.001$ & .011 & 12.232 & $<.001$ \\
\hline Education & -.013 & -24.842 & $<.001$ & -.013 & -24.842 & $<.001$ & -.013 & -24.979 & $<.001$ \\
\hline Political & -.028 & -32.369 & $<.001$ & -.028 & -32.369 & $<.001$ & -.029 & -32.860 & $<.001$ \\
\hline WvA & .152 & 147.404 & $<.001$ & .152 & 147.405 & $<.001$ & .139 & 59.197 & $<.001$ \\
\hline WAvO & -.003 & -4.616 & $<.001$ & -.003 & -4.616 & $<.001$ & -.002 & -2.611 & .009 \\
\hline \multicolumn{10}{|l|}{ Level 2} \\
\hline MR & -.057 & -13.237 & $<.001$ & -.053 & -12.372 & $<.001$ & -.053 & -12.388 & $<.001$ \\
\hline $\mathrm{V}$ & -.043 & -2.966 & .003 & -.029 & -2.054 & .041 & -.029 & -2.002 & .046 \\
\hline I & -.032 & -0.948 & .344 & -.029 & -0.883 & .378 & -.027 & -0.834 & .405 \\
\hline MR x V & & & & -.043 & -3.797 & $<.001$ & -.043 & -3.790 & $<.001$ \\
\hline MR x I & & & & .140 & 2.348 & .020 & .146 & 2.445 & .015 \\
\hline V x I & & & & -.161 & -1.005 & .316 & -.162 & -1.007 & .315 \\
\hline \multicolumn{10}{|l|}{ Cross-Level } \\
\hline WvA x MR & & & & & & & .009 & 2.799 & .006 \\
\hline WvA x V & & & & & & & -.014 & -1.397 & .164 \\
\hline WvA x I & & & & & & & .001 & 0.055 & .957 \\
\hline WvA x MR x V & & & & & & & .012 & 1.485 & .140 \\
\hline WvA x MR x I & & & & & & & -.082 & -1.981 & .050 \\
\hline WvA x V x I & & & & & & & .162 & 1.534 & .128 \\
\hline Level $1 r^{2}$ & .088 & & & & & & & & \\
\hline Level $2 r^{2}$ & .520 & & & .088 & & & .066 & & \\
\hline
\end{tabular}

Note. $\mathrm{MR}=$ Minority Representation, $\mathrm{V}=$ Variety, $\mathrm{I}=$ Integration. Level 1 fixed effects were group-mean centered and Level 2 fixed effects were grand-mean centered. Level $2 r^{2}$ values for Models 2 and 3 are additional variation explained by current than previous model (e.g., Model 2 v. Model 1). Gender was contrast-coded ( +1 if Male, -1 if Female). Participant ethnicity was coded in orthogonal codes: WvA (+1 if White, -1 if Asian, 0 if Other) and WAvO $(+1$ if White or Asian, -2 if Other). Political orientation was z-scored with higher values reflecting a more liberal orientation. 


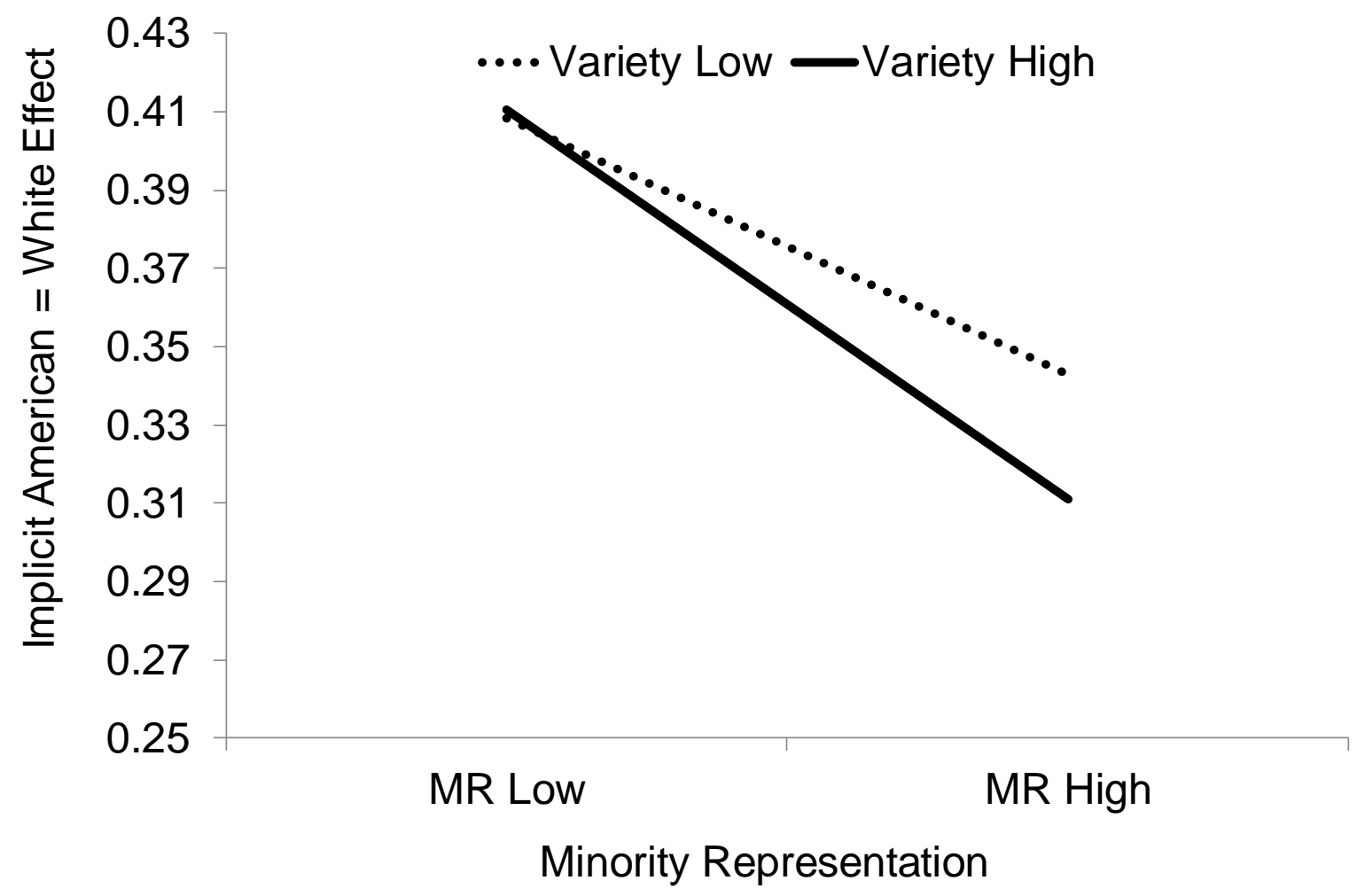

Figure 1. Implicit American $=$ White effect as a function of Minority Representation (MR) and Variety (I) across Metropolitan Statistical Areas (MSAs). 


\section{Supplemental Material}

Context Diversity Predicts the Extent to Which the American Identity Is Implicitly Associated with Asian Americans and European Americans

The main aim of the present work was to test the relations between three indicators of context diversity and implicit ethnic-American associations. Yet, it might be of interest to explore similar research questions in the realm of explicit ratings of Americanness. Evidence for an American $=$ White effect has also been obtained on explicit measures (Cheryan, \& Monin, 2005; Devos \& Banaji, 2005; Huynh, Devos, \& Altman, 2015; Nosek, Smyth, et al., 2007). In this supplemental material, we report analyses performed on an explicit measure that paralleled the IAT. Our goal was to provide a more comprehensive picture rather than to test a priori hypotheses regarding similarities or differences between implicit and explicit responses.

Participants who completed the Implicit Association Test were also asked to indicate which statement best describes their belief among seven options ranging from "I consider Americans of European descent to be much more American than Americans of Asian descent" $($ coded +3$)$ to "I consider Americans of Asian descent to be much more American than Americans of European descent" (coded -3). The mid-point of the response scale indicated the belief that both groups were equally American (coded 0). This single-item measure was introduced in 2006, thus, the sample for these analyses included $17.1 \%$ fewer cases than the implicit analyses reported in the main text.

This explicit measure of ethnic-American associations was analyzed using multilevel analyses similar to those described for the implicit measure $(I C C=.008$, see Table $S 1)$. The set of individual difference predictors accounted for $5.2 \%$ of the Level 1 variation in explicit ethnicAmerican associations (Model 1). On average, European Americans were perceived as more 
American than Asian Americans (as reflected in the intercept test). All the demographic variables were significant except for education, but all effects were very small (below the 3.0\% threshold).

The set of context diversity measures accounted for approximately $12.0 \%$ of the variation in (average) explicit beliefs between MSAs. Contrary to implicit findings, as the proportion of Asian Americans in an area increased, the explicit American $=$ White effect increased, $r^{2}=.092$. The effect of variety was significant and in the same direction as in the implicit analyses, but it was very small, $r^{2}=.015$. On the explicit measure, integration was source of a reliable effect: as integration increased, the explicit American $=$ White effect decreased, $r^{2}=.031$.

A model that allowed two-way interactions among the context diversity measures (Model 2) failed to provide a better fit to the data, $\chi^{2}(3)=1.405, n s$, and individual two-way interactions among context diversity measures were non-significant. In Model 3, there was one significant interaction between participant ethnicity and variety, but the effect size was of very small size, $r^{2}=.021$. Finally, the effect of minority representation, variety, and integration, remained significant and of the same relative size when population density, median income, and percentage of foreign-born people were introduced as context-level covariates. None of the additional context level variables had significant individual effects.

The pattern obtained at the explicit level is clearly distinct from what is observed at the implicit level. Most interesting is the fact that minority representation is a source of effects in the opposite direction at the implicit and explicit levels. As the portion of Asian Americans increases, this ethnic group is seen as relatively more American at the implicit level, but relatively less American at the explicit level. While integration is not a reliable source of 
variation in implicit associations, more integrated areas are characterized by weaker expressions of the perpetual foreigner stereotype than more segregated areas. This finding clearly suggests that integration, as operationalized here, is an important factor to consider when examining variations across contexts. Variety is source of more tenuous effects, but the direction of the effect is similar at both levels of responding: the presence of multiple ethnic groups is related to weaker stereotypes.

It is important to restate once again that comparing implicit and explicit ethnic-American associations was not a central goal of the present research. We report findings obtained on the explicit measures for completeness. Thus, it is wise not to overstate conclusions based on a comparison between these two levels. Although there is a substantive literature on the relations (similarities and differences) between implicit and explicit associations (Carlson, 2010;

Hofmann et al., 2005; Nosek, 2007), it is not clear that known moderators identified in previous research can easily account for the distinct patterns of relations between context diversity indicators and implicit vs. explicit associations obtained here. One intriguing possibility is that factors that may affect the socio-cognitive salience of Asian Americans might have contrasting implications at these two levels. As minority representation increases, Asian Americans may become more cognitively salient. At the implicit level, this may shift implicit default assumptions about who is seen as an American and weaken stereotypical responses. At the explicit level, in particular considering that Asian American in most cases remain a relatively small fraction of the overall population, greater cognitive salience may highlight their minority status and strengthen stereotypical responses. The fact that stronger explicit American $=$ White associations were observed in relatively segregated metropolitan areas is also consistent with 
this principle. Ethnic enclaves that characterize segregated settings may, at the explicit level, be associated with a distinctive status rather than an inclusion in the national identity.

At a minimum, these results call for a need to incorporate both levels of responding in future research to more fully understand differences and similarities between responses that are not consciously controllable and responses based on more deliberative processes. It is worth noting that the results based on the explicit measure also illustrate the usefulness of considering simultaneously distinct facets of contextual diversity. 


\section{References}

Carlston, D. (2010). Models of implicit and explicit mental representation. In B. Gawronski \& B. K. Payne (Eds.), Handbook of implicit social cognition: Measurement, theory, and applications (pp. 38-61). New York, NY: Guilford Press.

Cheryan, S., \& Monin, B. (2005). 'Where are you really from?': Asian Americans and identity denial. Journal of Personality and Social Psychology, 89(5), 717-730. doi:10.1037/00223514.89.5.717

Devos, T., \& Banaji, M. R. (2005). American = White? Journal of Personality and Social Psychology, 88(3), 447-466. doi:10.1037/0022-3514.88.3.447

Hofmann, W., Gawronski, B., Gschwendner, T., Le, H., \& Schmitt, M. (2005). A meta-analysis on the correlation between the Implicit Association Test and explicit self-report measures. Personality and Social Psychology Bulletin, 31(10), 1369-1385. doi:10.1177/0146167205275613

Huynh, Q. L., Devos, T., \& Altman, H. R. (2015). Boundaries of American identity: Relations between ethnic group prototypicality and policy attitudes. Political Psychology, 36(4), 449-468. doi:10.1111/pops.12189

Nosek, B. A. (2007). Implicit-explicit relations. Current Directions in Psychological Science, 16(2), 65-69. doi:10.1111/j.1467-8721.2007.00477.x

Nosek, B. A., Smyth, F. L., Hansen, J. J., Devos, T., Lindner, N. M., Ranganath, K. A., . . . Banaji, M. R. (2007). Pervasiveness and correlates of implicit attitudes and stereotypes. European Review of Social Psychology, 18(1), 36-88. doi: 10.1080/10463280701489053 
Table S1

Explicit Ethnic-American Associations as a Function of Context Diversity Dimensions.

\begin{tabular}{|c|c|c|c|c|c|c|c|c|c|}
\hline & & Model 1 & & & Model 2 & & & Model 3 & \\
\hline & $B$ & $t$ & $p$ & $B$ & $t$ & $p$ & $B$ & $t$ & $p$ \\
\hline \multicolumn{10}{|l|}{ Level 1} \\
\hline Intercept & .602 & 93.270 & $<.001$ & .602 & 77.635 & $<.001$ & .601 & 77.375 & $<.001$ \\
\hline Age & -.008 & -32.198 & $<.001$ & -.008 & -32.198 & $<.001$ & -.008 & -32.101 & $<.001$ \\
\hline Gender & -.011 & -4.809 & $<.001$ & -.011 & -4.809 & $<.001$ & -.010 & -4.711 & $<.001$ \\
\hline Education & -.001 & -0.695 & .487 & -.001 & -0.695 & .487 & -.001 & -0.686 & .493 \\
\hline Political & -.128 & -57.580 & $<.001$ & -.128 & -57.580 & $<.001$ & -.128 & -57.512 & $<.001$ \\
\hline WvA & -.187 & -7.437 & $<.001$ & -.187 & -7.436 & $<.001$ & -.166 & -22.482 & $<.001$ \\
\hline WAvO & .055 & 31.692 & $<.001$ & .055 & 31.692 & $<.001$ & .053 & 3.603 & $<.001$ \\
\hline \multicolumn{10}{|l|}{ Level 2} \\
\hline MR & .067 & 6.565 & $<.001$ & .069 & 6.397 & $<.001$ & .069 & 6.406 & $<.001$ \\
\hline V & -.099 & -2.843 & .005 & -.093 & -2.585 & .010 & -.093 & -2.588 & .010 \\
\hline I & -.304 & -3.750 & $<.001$ & -.285 & -3.465 & .001 & -.286 & -3.469 & .001 \\
\hline MR x V & & & & -.022 & -0.760 & .448 & -.022 & -0.765 & .445 \\
\hline MR x I & & & & -.066 & -0.437 & .662 & -.063 & -0.419 & .676 \\
\hline V x I & & & & -.207 & -0.512 & .609 & -.212 & -0.525 & .600 \\
\hline \multicolumn{10}{|l|}{ Cross-Level } \\
\hline WvA x MR & & & & & & & -.011 & -1.030 & .304 \\
\hline WvA x V & & & & & & & -.084 & -2.530 & .012 \\
\hline WvA x I & & & & & & & .108 & 1.426 & .156 \\
\hline WvA x MR x V & & & & & & & .036 & 1.292 & .199 \\
\hline WvA x MR x I & & & & & & & .070 & 0.500 & .618 \\
\hline WvA x V x I & & & & & & & -.498 & -1.392 & .167 \\
\hline Level $1 r^{2}$ & .052 & & & & & & & & \\
\hline Level $2 r^{2}$ & .120 & & & .006 & & & .046 & & \\
\hline
\end{tabular}

Note $. \mathrm{MR}=$ Minority Representation, $\mathrm{V}=$ Variety, $\mathrm{I}=$ Integration. Level 1 fixed effects were group-mean centered and Level 2 fixed effects were grand-mean centered. Level $2 r^{2}$ values for Models 2 and 3 are additional variation explained by current than previous model (e.g., Model 2 v. Model 1). Gender was contrast-coded ( +1 if Male, -1 if Female). Participant ethnicity was coded in orthogonal codes: WvA ( +1 if White, -1 if Asian, 0 if Other) and WAvO (+1 if White or Asian, -2 if Other). Political orientation was z-scored with higher values reflecting a more liberal orientation. 